\title{
A New High Order Fuzzy ARMA Time Series Forecasting Method by Using Neural Networks to Define Fuzzy Relations
}

\author{
Cem Kocak \\ The School of Health, Hitit University, 19000 Corum, Turkey \\ Correspondence should be addressed to Cem Kocak; cemkocak@hotmail.com
}

Received 12 August 2014; Accepted 24 September 2014

Academic Editor: Erol Egrioglu

Copyright ( 2015 Cem Kocak. This is an open access article distributed under the Creative Commons Attribution License, which permits unrestricted use, distribution, and reproduction in any medium, provided the original work is properly cited.

\begin{abstract}
Linear time series methods are researched under 3 topics, namely, AR (autoregressive), MA (moving averages), and ARMA (autoregressive moving averages) models. On the other hand, the univariate fuzzy time series forecasting methods proposed in the literature are based on fuzzy lagged (autoregressive (AR)) variables, having not used the error lagged (moving average (MA)) variables except for only two studies in the fuzzy time series literature. Not using MA variables could cause the model specification error in solutions of fuzzy time series. For this reason, this model specification error should be eliminated. In this study, a solution algorithm based on artificial neural networks has been proposed by defining a new high order fuzzy ARMA time series forecasting model that contains fuzzy MA variables along with fuzzy AR variables. It has been pointed out by the applications that the forecasting performance could have been increased by the proposed method in accordance with the fuzzy AR models in the literature since the proposed method is a high order model and also utilizes artificial neural networks to identify the fuzzy relation.
\end{abstract}

\section{Introduction}

The first fundamental definitions on fuzzy time series in the literature have been made by Song and Chissom [1] in accordance with the fuzzy set theory of Zadeh [2]. Song and Chissom $[1,3,4]$ divided fuzzy time series into two separate series, namely, time variant and time invariant. A vast majority of the studies in the literature are methodologies that have been proposed for solving time invariant fuzzy time series. The context of this study is also comprised of time invariant fuzzy time series.

The fuzzy time series models developed in the literature are AR (autoregressive) models only based on the fuzzy lagged values of time series, which are divided into two groups, namely, first order fuzzy time series forecasting methods and high order fuzzy time series forecasting methods. Among studies mentioned in the literature, studies of Song and Chissom [1, 3, 4], Chen [5], Huarng [6], Huarng and Yu [7, 8], Cheng et al. [9], Yolcu et al. [10], Yu and Huarng [11], Egrioglu et al. [12] and Sadaei and Lee [13] all used first order models for fuzzy time series solutions, while the studies of Chen [14], Chen and Chung [15], Jilani and Burney [16], Lee et al. [17], Aladag et al. [18], Egrioglu et al. [19, 20] and Sadaei et al. [21] used high order models. In addition, because some fuzzy time series contain seasonal relations, seasonal fuzzy time series forecasting methods also have been developed. Some of seasonal fuzzy time series models could be seen in the studies of Chang [22], Song [23], and Egrioglu et al. [24].

The majority of the studies in the literature are approaches towards improving the stages of fuzzification, identification of fuzzy relations, and defuzzification in order to increase forecasting performance. Regarding the stage of fuzzification, the approaches of Huarng [6] based on distribution and average, the optimization-based approach of Yolcu et al. [10], and the ratio-based approaches of Huarng and Yu [8] have brought a systematic view on the identification of interval length. Along with these, the approach of dividing the universe of discourse into equal intervals proposed initially by Song and Chissom [1] still maintains its validity and is used commonly in many studies. For the second stage called identification of fuzzy relations, this is also very effective in the forecasting performances of models, and different approaches have been proposed in the literature. Song and Chissom $[1,3,4]$ firstly have proposed approaches based on complex matrix operations in their studies. Thus, Chen [5] has proposed in his study a new approach that contains 
simpler operations where fuzzy logic group relation tables are without the need for the complex matrix operations of Song and Chissom $[1,3]$. Also, Chen [14] has brought a new approach by using the fuzzy logic group relation tables also in high order fuzzy time series models. Additionally, studies where fuzzy relations have identified via artificial neural networks have commonly observed. Studies where artificial neural networks have also been used for identifying fuzzy relations may be listed as the studies of Huarng and Yu [7], Aladag et al. [18], Egrioglu et al. [19, 24, 26], Yu and Huarng [11] and Yolcu et al. [25]. In the vast majority of studies within the literature, the centralization method has been used during the defuzzification stage.

The fuzzy time series forecasting methods developed in the literature have focused on the AR model. There has not been any study using MA and ARMA models except the studies of Egrioglu et al. [20], Uslu et al. [27], and Alpaslan et al. [28] until 2013 year. These studies [20, 27, 28] on the other hand are methods that have been proposed for the solution of seasonal time series. However, Egrioglu et al. [29] and Kocak [30] developed two different methods in the fuzzy ARMA type time series for the solution of nonseasonal time series in 2013 year. In these studies, Egrioglu et al.'s [29] study is the first of first order fuzzy ARMA type time series models based on particle swarm optimization in the fuzzy time series literature. Kocak's [30] study also is the second of first order fuzzy ARMA type models based on the group relation tables which are similar to Chen's approaches $[5,14]$ in identifying fuzzy relation.

All of the models expect these two studies $[29,30]$ in the literature have focused issues such as using the partitions of universe of discourse, membership order, model order, and artificial intelligence methods; however, no study has been taken notice of the model construction of fuzzy time series model for nonseasonal fuzzy time sets, whereas there are 3 different models used in the solutions of linear time series; namely, they are AR (autoregressive), MA (moving averages), and ARMA (autoregressive moving averages). Therefore, inclusion of only AR variables in the fuzzy time series forecasting models proposed in the literature could cause model specification error. Because modelling of many of the real-life time series requires using MA variables, thus, using only AR variables in the solution of many fuzzy time series might cause to be identified of fuzzy relations incorrectly and it also cause to the decrease of the forecasting performance.

In this study, ARMA type fuzzy time series models have been defined as a new model for eliminating the abovementioned adverse effects. A solution algorithm has been developed for high degree fuzzy $\operatorname{ARMA}(p, q)$ time series forecasting model where fuzzy relations are identified via artificial neural networks. The proposed method has been considered to be a significant study due to be the first of high order fuzzy ARMA models in the fuzzy time series literature. The advantages of the proposed algorithm are as follows.

(i) By also using MA variables along with AR variables in solutions, the model specification error is eliminated, and a more realistic approach is obtained for reallife time series. Thus, forecasting performance has significantly increased according to fuzzy AR models in the literature.

(ii) Since high degree fuzzy time series models take into consideration also the model order, usually the forecasting performance could be obtained to be better than first order methods. With the proposed method on the other hand, a forecasting performance can be obtained considerably higher than performances of fuzzy AR models in the literature because of the fact that both the AR and the MA variables are high order.

(iii) Using artificial neural networks has simplified the identification of fuzzy relations according to some methods $[1,5,14]$ and has been effective in increasing the forecasting performance.

In the second section of the study, the basic definitions of fuzzy time series have been presented, and basic information on artificial neural networks has been provided in the third section. In the fourth section, definitions with regard to the proposed method and the solution algorithm of the proposed method have been given. In the fifth section, results obtained through applying the proposed method and some other methods in the literature on Istanbul Stock Exchange (IMKB) national 100 index time series have been presented. In the sixth section, the results obtained from this paper have been discussed.

\section{Definition of Fuzzy Time Series}

Main time series definitions developed using AR variables are listed below.

Definition 1. Let $Y(t),(t=\ldots, 0,1,2, \ldots)$ be a real value time series, let $U$ be the universe of discourse in compliance with $Y(t)$, and let $f_{j}(t)$ (fuzzy subsets) be the subset functions identified in accordance with subintervals $\left(u_{j}\right)$ of $U$. If $F(t)$ is a collection of $f_{1}(t), f_{2}(t), \ldots, F(t)$ is called a fuzzy time series $[1,3,4]$.

Definition 2. Let $R(t, t-1)$ be the fuzzy relation between $F(t-$ 1 ) and $F(t)$. For any $t$ value, if there is the equal of $R(t, t-1)=$ $R(t-1, t-2)$, then $R(t, t-1)$ is independent from $t$. In that case, $F(t)$ is called the time invariant fuzzy time series [1].

Definition 3. If $F(t)$ is only affected by $F(t-1)$, then the fuzzy relation between $F(t-1)$ and $F(t)$ is expressed as

$$
F(t-1) \longrightarrow F(t)
$$

and is defined as a first order fuzzy time series forecasting model. The expression in (1), showing the fuzzy relation between $R(t, t-1), F(t-1)$, and $F(t)$, can also be expressed as

$$
F(t)=F(t-1) \circ R(t, t-1) .
$$

The "o" operator in (2) had been determined as the max-min operator by Song and Chissom [1]. 


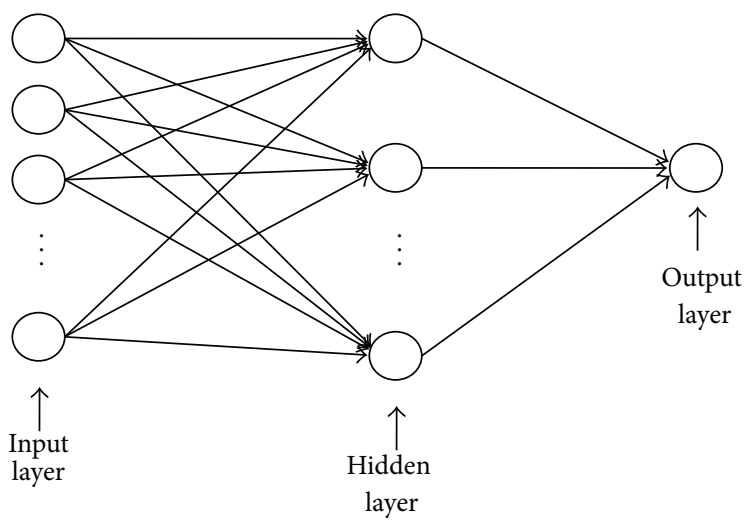

FIGURE 1: Multilayer FFANN with one output neuron.

Definition 4. If $F(t)$ is affected by $F(t-1), F(t-2), \ldots, F(t-$ $p$ ) which are lagged fuzzy time series, then the fuzzy relation between $F(t)$ and the $F(t-1), F(t-2), \ldots, F(t-p)$ fuzzy time series may be expressed as

$$
F(t-p), \ldots, F(t-2), F(t-1) \longrightarrow F(t)
$$

and is called the $p$ th order fuzzy time series forecasting model [14].

\section{Feedforward Artificial Neural Networks (FFANN)}

Artificial neural networks (ANN) can be defined as algorithms developed by inspiration from biological neural networks in order to provide the skills of the human brain such as producing new information and discovery through learning [31, 32]. ANN, besides being an intuitive technique aiming optimization, is used for the purposes of classification, estimation, and modelling in identification of functional relations.

There are two fundamental architectures in the contemporary ANN. These are feedback ANN and feedforward ANN. Feedback ANN (FBANN) is used for solution exploration for optimisation problems. Feedforward ANN (FFANN), on the other hand, is used commonly in identifying relations between variables. A FFANN architecture may be seen in Figure 1.

Main components of the FFANN seen in Figure 1 are as follows.

3.1. Architecture Structure. A FFANN network consists of one input layer, one output layer, and one or more hidden layers. Each layer has one or more neurons. Connections are unidirectional and forward oriented. The neuron values on the input layer are sent to the neurons on the hidden layer. The neuron values on each layer transmit value to the neuron on the following layer. Thus, the neuron values on the output layer are obtained in the final stage.

3.2. Learning Algorithm. Learning of FFANN is a process of adjusting weights as to perform a desired process. Learning algorithms used in FFANNs aim to specify the weights that would minimise the error. Studies conducted on gradientbased approaches are still used for the learning of nonlinear events through FFANN. Backpropagation learning, one of these approaches, is commonly used in our day. One of the backpropagation algorithms, Levenberg-Marquardt algorithm [33], has certain positive qualities that eliminate some limitations of its predecessor methods of gradient decrease and Newton [34]. Therefore, Levenberg-Marquardt algorithm has been used while fuzzy relations are determined with FFANN in this study.

3.3. Activation Function. Inputs coming to the neurons on the hidden layer or output layers are obtained that the outputs of neurons on the previous layer are multiplied with relevant weights and summed up. The information received at these neurons is processed through an activation function to obtain the output of the neuron. Activation function provides curvilinear matchup. Therefore, nonlinear activation functions are used for hidden layer units. The nonlinear activation function most commonly used in the analysis of fuzzy time series is the logistic activation function. For this reason, logistic activation function has been used while fuzzy relations are determined with FFANN in this study.

\section{The Proposed Method}

Not utilizing MA variables in the fuzzy time series models has caused model specification error. Thus, it is necessary to develop fuzzy ARMA models that also include MA variables for the solution of fuzzy time series. Due to this necessity, the high order fuzzy ARMA time series forecasting method based on artificial neural networks has been proposed within the context of this study. The proposed method could be considered to be leading for future studies due to being the first of high order fuzzy ARMA model in the fuzzy time series literature. The high order fuzzy ARMA time series model to be used in the solution algorithm of the proposed method is as below.

Definition 5. Let there be $F(t), n$ observed fuzzy time series and $\varepsilon(t)$, fuzzy error series obtained from $F(t)$. As $p, q \leq n$, if $F(t)$ is affected from both the lagged $F(t-1), F(t-2), \ldots, F(t-$ $p$ ) fuzzy time series and the lagged $\varepsilon(t-1), \varepsilon(t-2), \ldots, \varepsilon(t-q)$ fuzzy time series, then the fuzzy relation between $F(t)$ fuzzy time series, $F(t-1), F(t-2), \ldots, F(t-p)$ fuzzy time series, and $\varepsilon(t-1), \varepsilon(t-2), \ldots, \varepsilon(t-q)$ fuzzy error series could be expressed with the below expression:

$$
\begin{gathered}
F(t-p), \ldots, F(t-2), F(t-1), \varepsilon(t-q), \ldots, \\
\quad \varepsilon(t-2), \varepsilon(t-1) \longrightarrow F(t)
\end{gathered}
$$

and is defined as high order $\operatorname{ARMA}(p, q)$ fuzzy time series forecasting model. Here, $p$ gives the order of AR variable, and $q$ gives the order of MA variable.

In expression (4) within Definition 5, when the value 1 is put in $p$ and $q$, the first order fuzzy $\operatorname{ARMA}(1,1)$ time series forecasting model given in Definition 6 below is obtained. 
TABLE 1: An example for the determination of fuzzy relations for the fuzzy AR(3) model.

\begin{tabular}{lccccccc}
\hline$F(t-3)$ & $F(t-2)$ & $F(t-1)$ & $F(t)$ & Input 1 & Input 2 & Input 3 & Target \\
\hline A5 & A1 & A4 & A3 & 5 & 1 & 4 & 3 \\
A1 & A4 & A3 & A2 & 1 & 4 & 3 & 2 \\
A4 & A3 & A2 & A6 & A5 & 3 & 2 & 2 \\
A3 & A2 & A6 & A & 5 & 6 \\
\hline
\end{tabular}

Definition 6. Let $F(t)$ be a fuzzy time series and let $\varepsilon(t), F(t)$ be the fuzzy error series obtained from the fuzzy time series. If $F(t)$ is affected by one lagged $F(t-1)$ and one lagged $\varepsilon(t-1)$ fuzzy error series, the fuzzy relation between $F(t), F(t-1)$ and $\varepsilon(t-1)$ fuzzy could be expressed as

$$
F(t-1), \varepsilon(t-1) \longrightarrow F(t)
$$

and is defined as the first order autoregressive moving averages $(\operatorname{ARMA}(1,1))$ fuzzy time series forecasting model [29, 30].

The fuzzy $\operatorname{ARMA}(p, q)$ model given in expression (4) can be considered a general high order model that also covers the first order fuzzy $\operatorname{ARMA}(1,1)$ model given in expression (5). In this study, an algorithm has been proposed for solving the high order fuzzy $\operatorname{ARMA}(p, q)$ time series forecasting model defined in expression (4). In the proposed algorithm, the fuzzy $\operatorname{AR}(p)$ model defined in (3) has been forecasted, and the errors are calculated by using time series and defuzzified forecasts obtained from fuzzy $\operatorname{AR}(p)$ model. Then, the fuzzy $\operatorname{ARMA}(p, q)$ model given in $(4)$ has been forecasted. The algorithm of the proposed approach is given below.

\subsection{The Algorithm of the Proposed Method}

Step 1 (the universe of discourse $(U)$ and subintervals $\left(u_{i}\right.$, $i=1,2, \ldots, b)$ are defined). Starting and ending points of $U$ are defined. Then the universal set is divided into subintervals $\left(u_{i}\right)$ according to appropriate interval length. Definition of interval length is important to the researcher. It should not be forgotten that the interval length to be determined affects the number of subintervals $(b)$. If the smallest value of the time series is taken as $Y_{\min }$, largest value as $Y_{\max }$, and two arbitrary values as $D_{1}$ and $D_{2}$, the universal set can be defined as the closed interval of

$$
U=\left[Y_{\min }-D_{1}, Y_{\max }+D_{2}\right] .
$$

$u_{i}$ subintervals determined for $i=1,2, \ldots, b$ are the subintervals of the universal set $U$, which is defined as

$$
U=\left\{u_{1}, u_{2}, \ldots, u_{b}\right\} .
$$

Step 2. For the time series, fuzzy sets are defined according to the universe of discourse $(U)$ and the partitions $\left(u_{i}\right)$. These fuzzy sets are expressed as

$$
\begin{array}{r}
A_{i}=\frac{f_{A_{i}}\left(u_{1}\right)}{u_{1}}+\frac{f_{A_{i}}\left(u_{2}\right)}{u_{2}}+\cdots+\frac{f_{A_{i}}\left(u_{b}\right)}{u_{b}}, \\
\text { for } i=1,2, \ldots, b .
\end{array}
$$

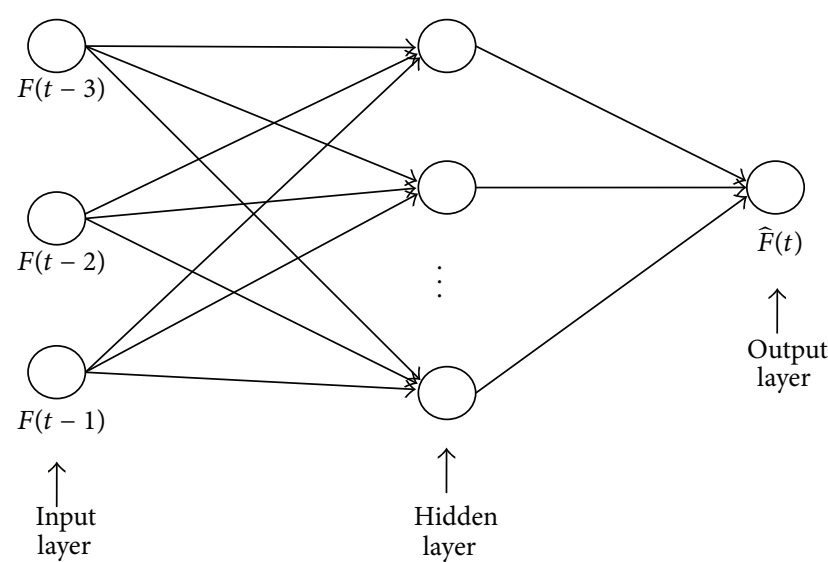

FIGURE 2: The architectural structure of FFANN for fuzzy AR(3) model.

Here, for $i=1,2, \ldots, b$,

$$
f_{A_{i}}\left(u_{i}\right)= \begin{cases}1, & k=i \\ 0.5, & k=i-1, i+1 \\ 0, & \text { otherwise. }\end{cases}
$$

Step 3 (time series $Y(t)$ is fuzzified). Subintervals $\left(u_{i}\right)$ where each observation occurs are defined. Then the fuzzy set $A_{i}$ where the defined subinterval has the highest membership value is defined. The fuzzy value of the observation is this $A_{i}$.

Step 4 (for the fuzzy $\operatorname{AR}(p)$ model, fuzzy relations are determined via feedforward artificial neural network (FFANN)). For the purposes of identifying relations via FFANN, the lagged fuzzy time series variables $F(t-p), \ldots, F(t-2), F(t-1)$ are the inputs of FFANN, and $\widehat{F}(t)$ is the output of FFANN, where the fuzzy time series $F(t)$ is the target value. The training samples of FFANN are comprised of the sequence numbers of the fuzzy sets. For example, let the fuzzy time series observations be, respectively, A5, A1, A4, A3, A2, A6, and A5. In Table 1 , the inputs and target value of the artificial neural network for this example as per fuzzy AR(3) model are displayed.

The architectural structure of FFANN used in this step for fuzzy relation identification regarding the example given in Table 1 is shown in Figure 2.

For the training of FFANN, the Levenberg-Marquardt learning algorithm is utilised, and the following logistic 
activation function is used for the calculation of each neuron value:

$$
f(\text { net })=\frac{1}{1+\exp (- \text { net })} .
$$

Step 5 (fuzzy forecasts are obtained). The output of FFANN of which architectural structure is given in Figure 2 is the sequence numbers of the fuzzy sets. The fuzzy sets with these sequence numbers form the fuzzy forecasts. For example, if the output of the artificial neural network is obtained as 5 when rounded up or down, the fuzzy forecast will be found as $A_{5}$.

Step 6 (defuzzification process is executed). In this step, centralisation method is utilised. When the fuzzy forecast is $A_{i}$, the defuzzified forecast becomes the middle point of the $u_{i}$ interval that has the highest membership value within $A_{i}$.

Step 7. Errors are calculated by taking the differences between the observed time series values and the defuzzified forecast values obtained in Step 6. Real values of the time series are $Y(t)$ and the defuzzified forecast values obtained in Step 6 are $\widehat{Y}(t)$; the error series $e(t)$ is calculated as follows:

$$
e(t)=Y(t)-\widehat{Y}(t) .
$$

For example, if the error values of the first 3 observations for the fuzzy AR(3) model are assumed as 0 , the errors from the 4 th to the last observation are calculated with Formula (11).

Step 8 (for the errors, the universe of discourse is defined as $(V)$ and subintervals are defined as $\left.v_{j}(j=1,2, \ldots, c)\right)$. Starting and ending points of $V$ are defined. Then $V$ is divided into subintervals according to appropriate interval length. If the smallest value of the time series is taken as $e_{\min }$, largest value as $e_{\max }$, and two arbitrary values as $D_{1}$ and $D_{2}$, the universe of discourse can be defined as the closed interval of

$$
V=\left[e_{\min }-D_{1}, e_{\max }+D_{2}\right] .
$$

The $v_{i}$ subintervals determined for $j=1,2, \ldots, c$ are the subintervals of the universal set $V$, expressed as

$$
V=\left\{v_{1}, v_{2}, \ldots, v_{c}\right\} .
$$

Step 9 (fuzzy sets based on the universe of discourse $(V)$ and partitions $\left(v_{j}\right)$ are defined for the errors). The fuzzy sets are expressed, based on the explanations in Definition 1, as follows:

$$
\begin{array}{r}
B_{j}=\frac{f_{B_{j}}\left(v_{1}\right)}{v_{1}}+\frac{f_{B_{j}}\left(v_{2}\right)}{v_{2}}+\cdots+\frac{f_{B_{j}}\left(v_{c}\right)}{v_{c}}, \\
\text { for } j=1,2, \ldots, c .
\end{array}
$$

Here, for $j=1,2, \ldots, c$,

$$
f_{B_{j}}\left(v_{j}\right)= \begin{cases}1, & k=j \\ 0.5, & k=j-1, j+1 \\ 0, & \text { otherwise. }\end{cases}
$$

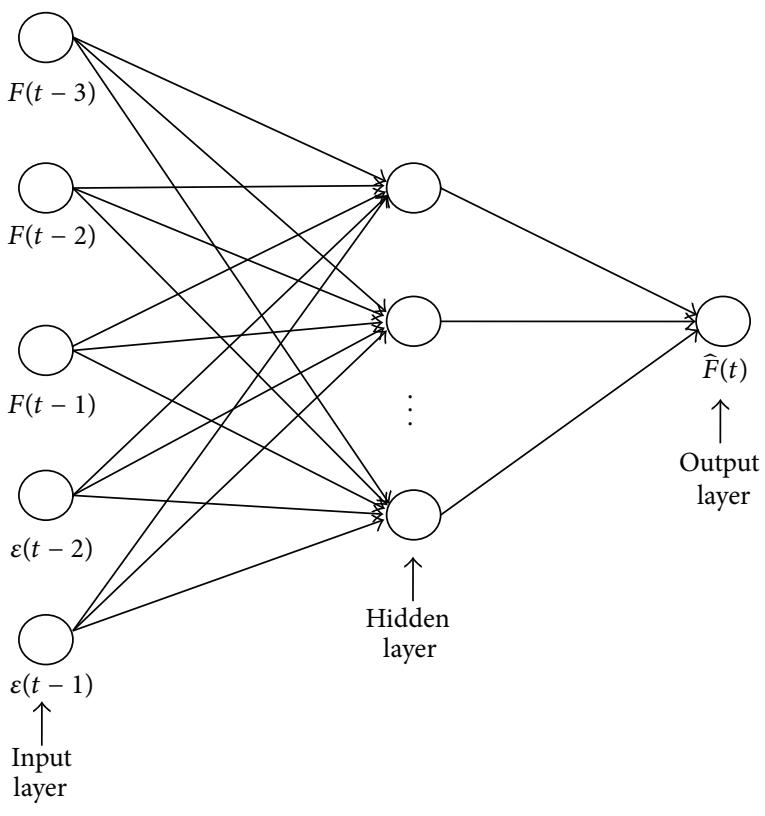

FIGURE 3: The architectural structure of FFANN used for fuzzy $\operatorname{ARMA}(3,2)$ model.

Step 10 (error series $e(t)$ is fuzzified). Subintervals $\left(v_{j}\right)$ for each error value are determined. Then the fuzzy set $B_{j}$ where the determined subinterval has the highest membership value is defined. Fuzzy value of the error value is this $B_{j}$ fuzzy set of which value was determined.

Step 11 (fuzzy relations for the fuzzy $\operatorname{ARMA}(p, q)$ model are determined via feedforward artificial neural network $($ FFANN)). For the purposes of identifying relations via FFANN, the lagged fuzzy time series variables $F(t-p), \ldots$, $F(t-2), F(t-1)$ and the fuzzy error series variables $\varepsilon(t-p)$, $\ldots, \varepsilon(t-2), \varepsilon(t-1)$ are the inputs of FFANN, and $\widehat{F}(t)$ is the output of the artificial neural network where the fuzzy time series $F(t)$ is the target value. Learning examples of FFANN are comprised of the sequence numbers of the fuzzy sets. For example, let the fuzzy time series observations be, respectively, A5, A1, A4, A3, A2, A6, and A5 and let the fuzzy error series observations be, respectively, B3, B3, B3, B2, B4, B3, B5, and B6. In Table 2, the inputs and target value of FFANN for this example as per fuzzy $\operatorname{ARMA}(3,2)$ model are displayed.

The architectural structure of the feedforward artificial neural network used in this step for fuzzy relation identification regarding the example given in Table 2 is shown in Figure 3.

For the training of FFANN, the Levenberg-Marquardt learning algorithm is utilised, and the logistic activation function given in expression (10) is used for the calculation of each neuron value.

Step 12 (fuzzy forecasts are obtained). The output of FFANN of which architectural structure is given in Figure 3 is the sequence numbers of the fuzzy sets. The fuzzy sets with these sequence numbers form the fuzzy forecasts. For example, if 
TABLE 2: An example for the determination of fuzzy relations for fuzzy ARMA(3,2) model.

\begin{tabular}{lcccccccccccc}
\hline$F(t-3)$ & $F(t-2)$ & $F(t-1)$ & $F(t)$ & $\varepsilon(t-2)$ & $\varepsilon(t-1)$ & Input 1 & Input 2 & Input 3 & Input 4 & Input 5 & Target \\
\hline A5 & A1 & A4 & A3 & B3 & B3 & 5 & 1 & 4 & 3 & 3 & 3 \\
A1 & A4 & A3 & A2 & B3 & B2 & 1 & 4 & 3 & 3 & 2 \\
A4 & A3 & A2 & A6 & B2 & B4 & 4 & 3 & 2 & 2 & 4 \\
A3 & A2 & A6 & A5 & B4 & B3 & 3 & 2 & 6 & 4 & 3 \\
\hline
\end{tabular}

the output of FFANN is obtained as 5 when rounded up or down, the fuzzy forecast will be found as $A_{5}$.

Step 13 (defuzzification process is executed). In this step, centralisation method is utilised. When the fuzzy forecast obtained in Step 12 is $A_{i}$, the defuzzified forecast becomes the middle point of the $u_{i}$ interval that has the highest membership value within $A_{i}$.

\section{Application}

For the application of the proposed method and the methods in literature, by increasing one unit the number of fuzzy sets of times series and the number of fuzzy sets of error series that are between 5 and 35, a total of 31 different numbers of fuzzy sets have been tried. If the method required calculation according to interval length, the interval lengths have been determined as to have the number of fuzzy sets comply with the interval of 5-35, using the formula below:

$$
\text { Interval Length }=\frac{\max (\text { data })-\min (\text { data })}{\text { Number of Fuzzy Sets }} .
$$

The number of hidden layer units of the feedforward artificial neural networks used in the 4 th and 11th steps of the proposed method has been varied between 1 and 10. LevenbergMarquardt has been used for the training of the artificial neural network, and the logistic activation function given in (10) has been used for the hidden layer units and output layer. Forecasts that make the value of the RMSE (root mean square error) given in (17) minimum have been obtained as the best results of the method:

$$
\operatorname{RMSE}=\left(\frac{\sum_{i=1}^{T}\left(y_{i}-\widehat{y}_{i}\right)^{2}}{T}\right)^{1 / 2} .
$$

According to RMSE scale, the values of MAPE (mean average percentage error) and DA (Direction Accuracy) values are also calculated as given in the below equations of (18) for the best results of all methods:

$$
\begin{gathered}
\text { MAPE }=\frac{1}{T} \sum_{i=1}^{T}\left|\frac{y_{i}-\hat{y}_{i}}{y_{i}}\right|, \\
\mathrm{DA}=\frac{1}{T} \sum_{i=1}^{T} a_{i}, \quad a_{i}= \begin{cases}1 & \text { if }\left(y_{i+1}-y_{i}\right)\left(\hat{y}_{i+1}-y_{i}\right)>0 \\
0 & \text { otherwise. }\end{cases}
\end{gathered}
$$

We divide the data of Istanbul Stock Exchange (IMKB) national 100 index (IMKB) into three parts to compare the

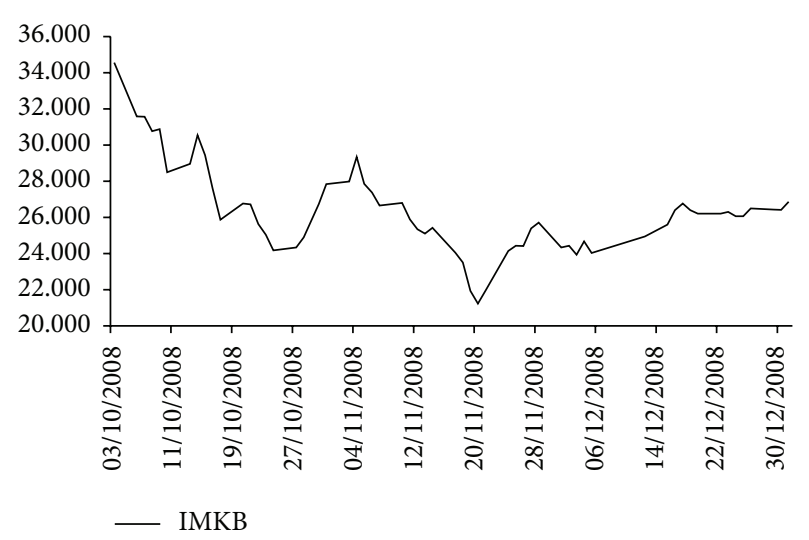

FIgURE 4: The time series graph of data set 1 , the period between 03.10.2008 and 31.12.2008.

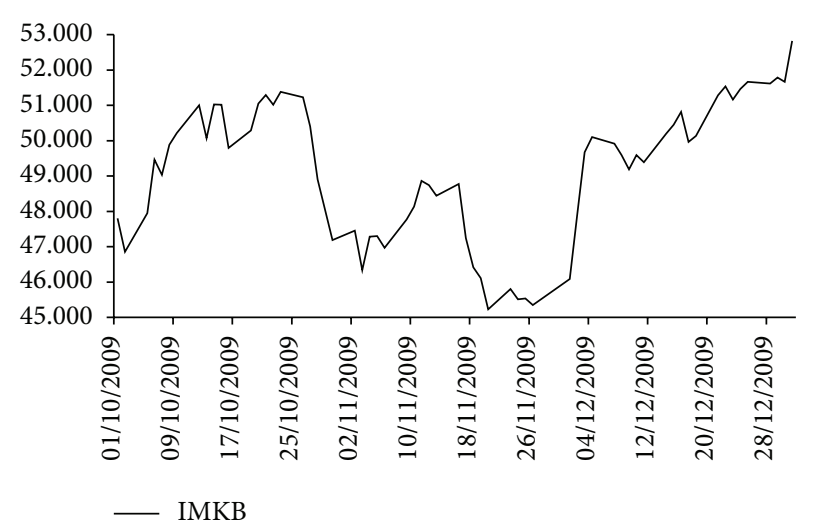

FIGURE 5: The time series graph of data set 2, the period between 01.10.2009 and 31.12.2009.

results to ones to be obtained from the methods in the literature. Two different sizes for the test data were tried out to every data set. Consequently 6 different analyses have been done. The periods, 03/10/2008-31/12/2008, 01/10/2009$31 / 12 / 2009$, and $01 / 10 / 2010-23 / 12 / 2010$ of IMKB were referred as data sets 1,2 , and 3 , respectively. The time series graphs of the data sets are given in Figures 4, 5, and 6, respectively.

By taking the last 7 observations in the first solution of the data belonging to data set 1 , data set 2 , and data set 3 with the methods in the literature, and taking the last 15 observations in the second solution as test set, a total of 6 different applications have been realised. For the solution of the data with the AR models in the literature, consider the following. 


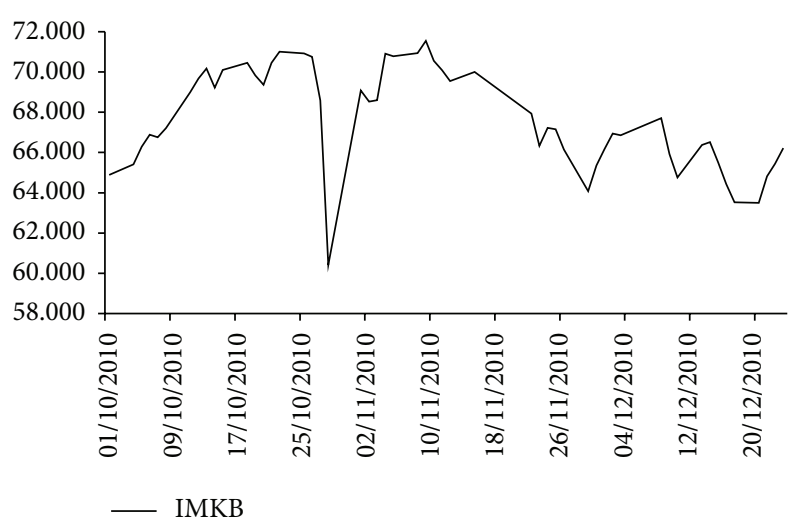

FIGURE 6: The time series graph of data set 3, the period between 01.10.2010 and 23.12.2010.

(i) During the fuzzification stage of Song-Chissom's AR(1) model [1], 31 different results have been obtained from increasing the fuzzy set number between 5 and 35 . The test set forecast that has the minimum RMSE value from these results has been determined as the best result of the method.

(ii) For each of Chen's $\operatorname{AR}(1)[5]$ and Chen's $\operatorname{AR}(p)(p=$ $1,2, \ldots, 5)[14]$ models, the RMSE values have been found for different results with the interval length being increased 100 units between 400 and 2700 for data set 1 , between 200 and 1600 for data set 2 , and between 300 and 2300 for data set 3 . The test set forecasts that have the minimum RMSE values among these results have been determined as the best results of the methods.

(iii) For Aladag et al.s $\operatorname{AR}(p)(p=1,2, \ldots, 5)[18]$ model, the RMSE values have been found for different results with the interval length being increased 100 units between 400 and 2700 for data set 1, between 200 and 1600 for data set 2, and between 300 and 2300 for data set 3 and by increasing the number of units for hidden layers of the feedforward artificial neural network 1 unit between 1 and 10. The test set forecasts that have the minimum RMSE values among these results have been determined as the best results of the methods.

(iv) By using the optimal interval lengths calculated via the distribution-based approach and averagebased approach of Huarng [6] and the average-based approaches, solution has been applied as per the first order fuzzy time series forecast method of Chen [5]. Thus, the best results of the test set from the distribution based approach and the average-based approaches have been obtained via a single trial.

(v) In the application of the ratio-based approach of Huarng and $\mathrm{Yu}[8]$, alpha parameter has been taken 0.50 . Then, the best result for the test set of the method has been obtained in one trial.

(vi) The best forecasts of Cheng et al. [9] and Yolcu et al. [25] methods have been taken from the study of Yolcu et al. [25].
Processes which were made for the solution of the data with using the proposed method are as follows.

(i) During the fuzzification stage in Step 1 for the IMKB time series, different trials have been done with the interval length being increased 100 units between 400 and 2700 for data set 1, between 200 and 1600 for data set 2 , and between 300 and 2300 for data set 3 .

(ii) While different trials have been made in Step 1, different forecasts have been obtained for $\operatorname{AR}(p)(p=$ $1,2, \ldots, 5)$ model, by increasing the number of hidden layers of the feedforward artificial neural network by 1 unit between 1 and 10 and trying different interval lengths in Step 4.

(iii) Among the different forecasts, the forecast that has minimum RMSE value for test set is determined as the best result of $\mathrm{AR}(p)$.

(iv) For the best forecast of the time series, the error series $(e(t))$ has been calculated by using Formula (11) in Step 7.

(v) During the fuzzification stage of errors, 31 different trials have been done by increasing the number of fuzzy sets belonging to $e(t)$ error series between 5 and 35 by 1 unit.

(vi) For the identification of fuzzy relations in Step 11 for the second time, forecasts with different performances have been obtained for $\operatorname{ARMA}(p, q)(p$ and $q=1,2, \ldots, 5)$ model by increasing the number of units for hidden layers of the feedforward artificial neural network 1 unit between 1 and 10 , and by trying different interval lengths of time series and fuzzy set numbers of error series.

(vii) The test set forecast with the smallest RMSE value among these forecasts has been determined as the best result of the proposed method.

The best forecasts and forecasting performances obtained for the test set of the methods have been presented in Tables 3-8. Also the graphs of the best forecasts obtained for the test set via the proposed method are displayed in Figures 7-12.

The parameters during which the best results given in Table 3 were obtained are as follows:

(i) when the number of fuzzy sets is 9 for the solution of Song and Chissom [1] method,

(ii) when the interval length is 400 for the solution of Chen [5] method,

(iii) when the interval length on 3rd degree model is 400 for the solution of Chen [14] method,

(iv) when the interval length is 800 for Huarng's distribution-based approach [6],

(v) when the interval length is 200 for Huarng's distribution-based approach [6],

(vi) when the sample percentile is 0.5 for Huarng's ratiobased approach [8], 

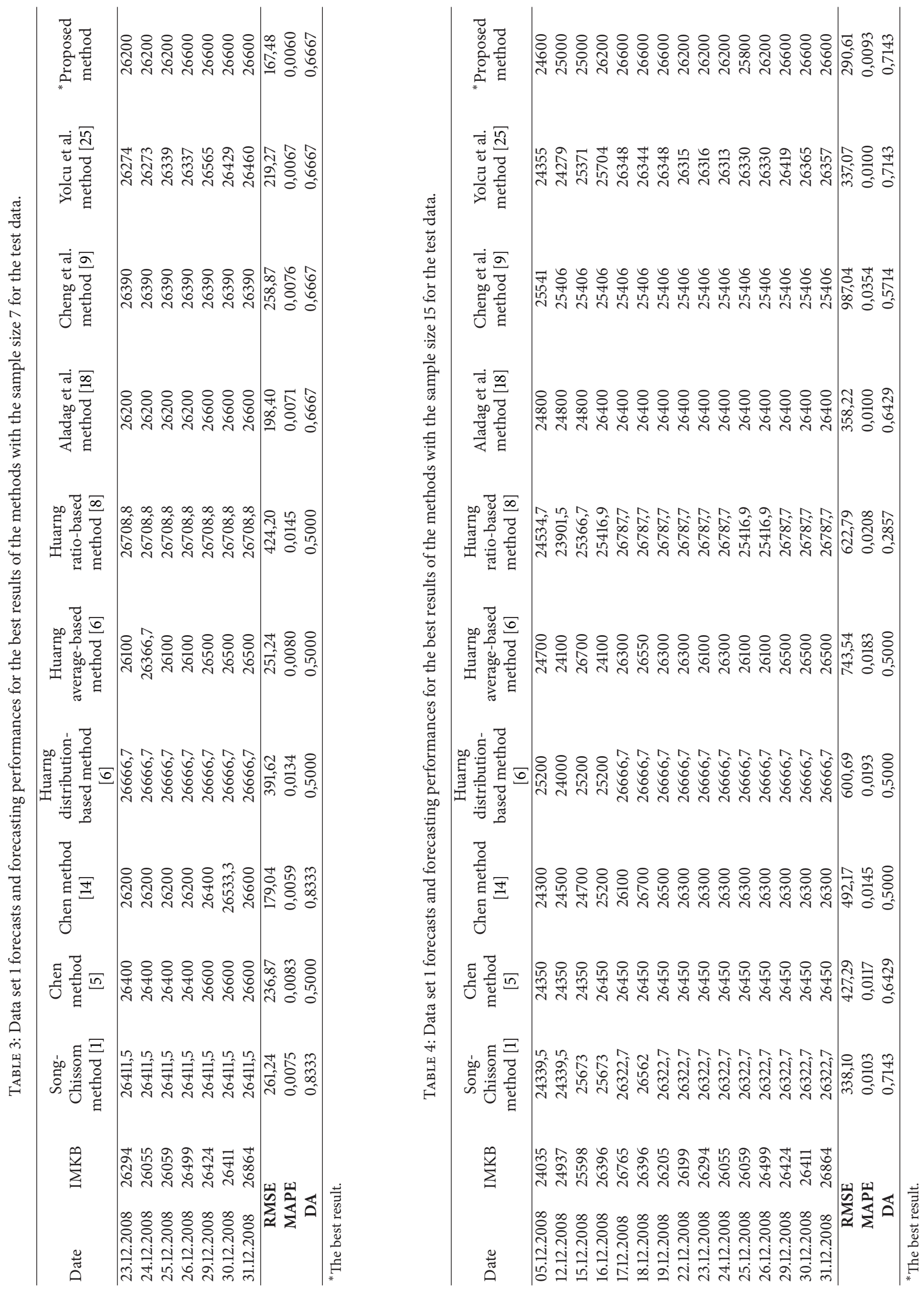

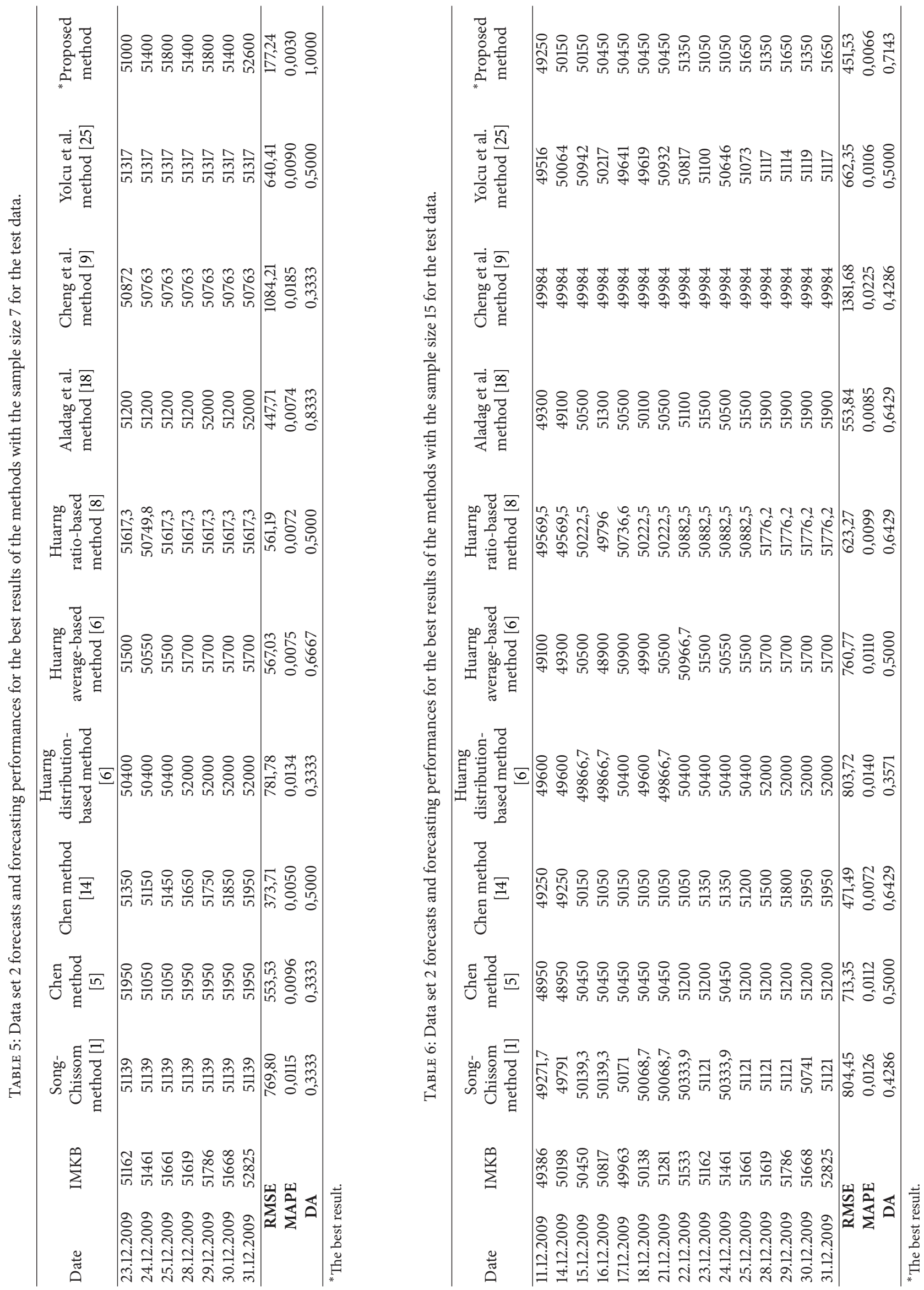

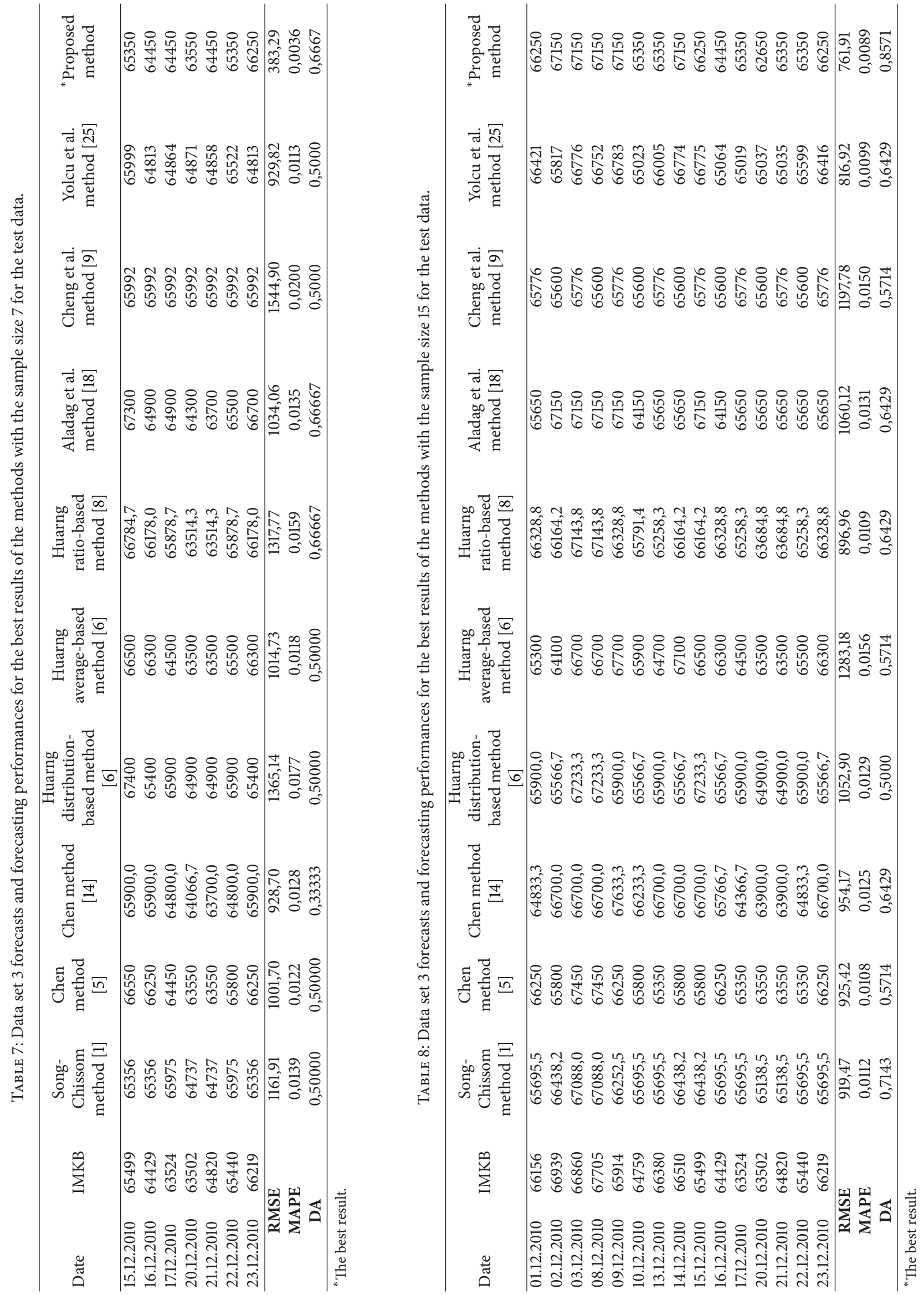


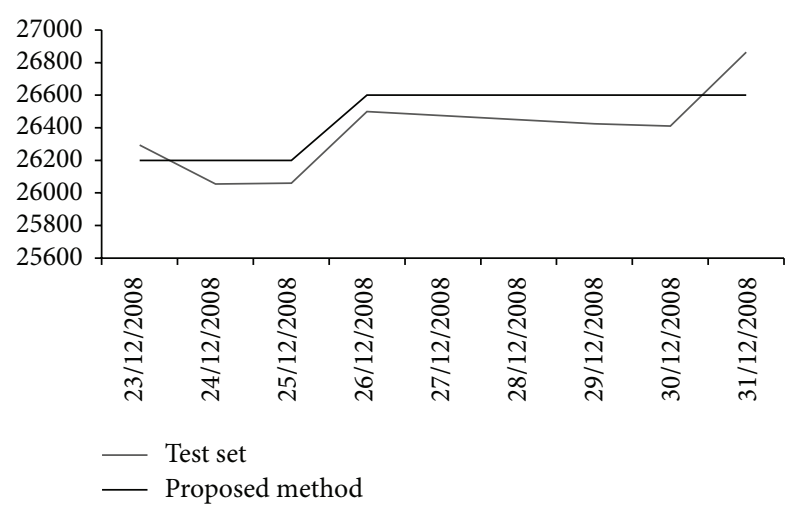

Figure 7: The graph of 7-observation test set of data set 1 and the forecasts of the proposed methods.

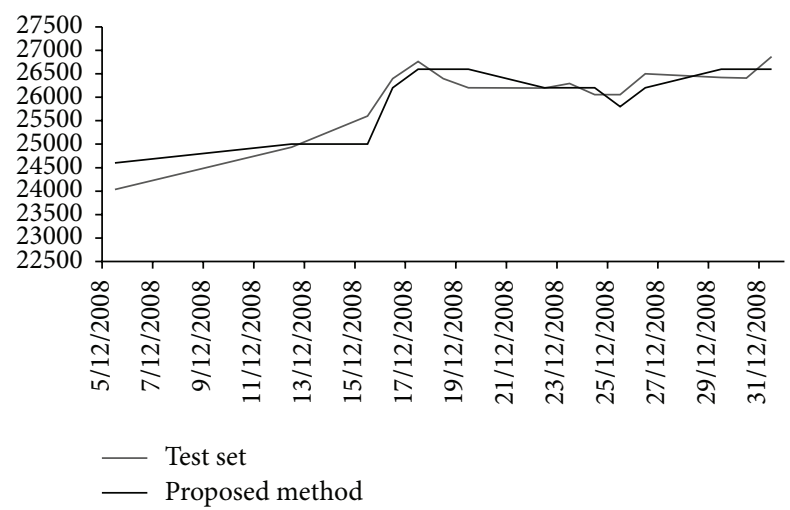

FIgURE 8: The graph of 15-observation test set of data set 1 and the forecasts of the proposed methods.

(vii) when the interval length is 400 on 2 nd degree model and unit number of artificial neural network hidden layers is 1 for the solution of Aladag et al. [18] method,

(viii) when the number of fuzzy sets is 5 for the solution of Cheng et al. [9] method,

(ix) when the number of fuzzy sets is 11 and the unit number of artificial neural network hidden layers is 5 for the solution of Yolcu et al. [25] method,

(x) when the interval length is 400 for time series $(Y(t))$, the number of fuzzy sets is 11 for error series $(e(t))$, and the unit number of artificial neural network hidden layers is 1 in the fuzzy $\operatorname{ARMA}(5,5)$ model for the solution of the proposed method.

The parameters during which the best results given in Table 4 were obtained are as follows:

(i) when the number of fuzzy sets is 15 for the solution of Song and Chissom [1] method,

(ii) when the interval length is 2100 for the solution of Chen [5] method,

(iii) when the interval length on 2nd degree model is 600 for the solution of Chen [14] method,

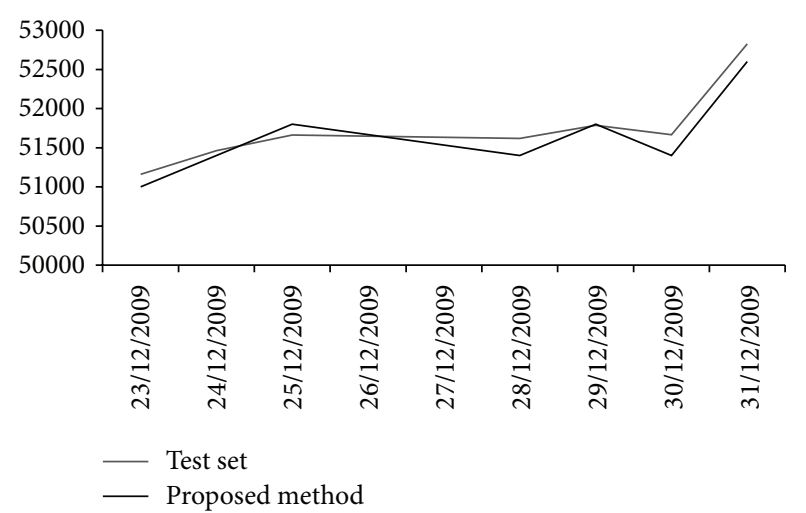

FIGURE 9: The graph of 7-observation test set of data set 2 and the forecasts of the proposed methods.

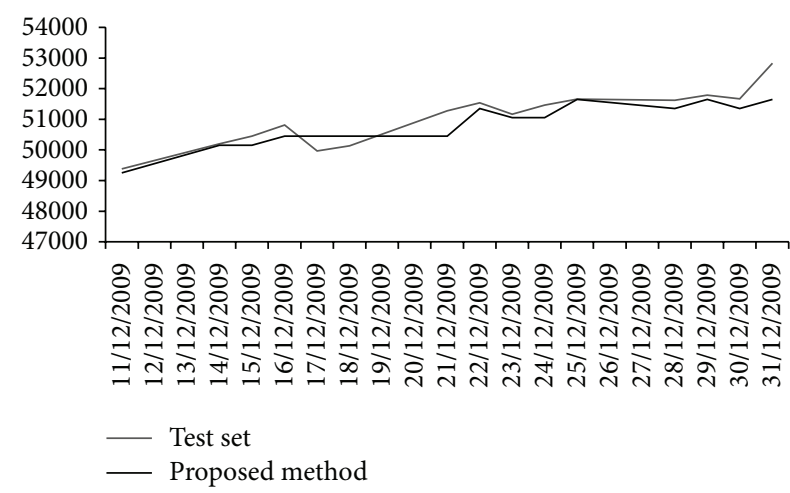

FIGURE 10: The graph of 15-observation test set of data set 2 and the forecasts of the proposed methods.

(iv) when the interval length is 800 for Huarng's distribution-based approach [6],

(v) when the interval length is 200 for Huarng's averagebased approach [6],

(vi) when the sample percentile is 0.5 for Huarng's ratiobased approach [8],

(vii) when the interval length is 800 on 5th degree model and unit number of artificial neural network hidden layers is 2 for the solution of Aladag et al. [18] method,

(viii) when the number of fuzzy sets is 9 for the solution of Cheng et al. [9] method,

(ix) when the number of fuzzy sets is 12 and the unit number of artificial neural network hidden layers is 2 for the solution of Yolcu et al. [25] method,

(x) when the interval length is 400 for $Y(t)$, the number of fuzzy sets is 19 for $e(t)$, and the unit number of artificial neural network hidden layers is 2 in the fuzzy $\operatorname{ARMA}(3,5)$ model for the solution of the proposed method.

The parameters during which the best results given in Table 5 were obtained are as follows: 


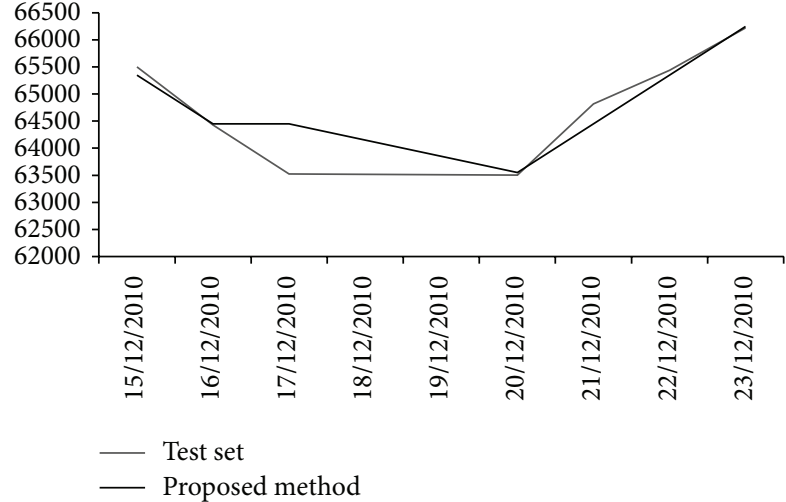

FIGURE 11: The graph of 7-observation test set of data set 3 and the forecasts of the proposed methods.

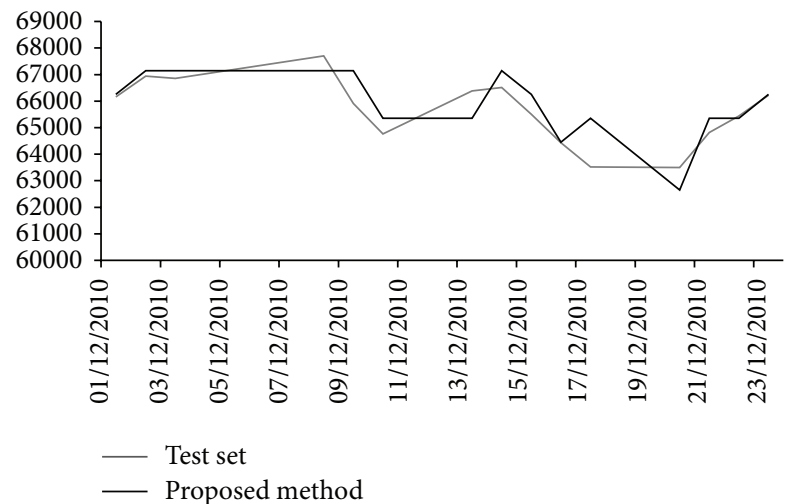

FIGURE 12: The graph of 15-observation test set of data set 3 and the forecasts of the proposed methods.

(i) when the number of fuzzy sets is 9 for the solution of Song and Chissom [1] method,

(ii) when the interval length is 900 for the solution of Chen [5] method,

(iii) when the interval length on 5th degree model is 1500 for the solution of Chen [14] method,

(iv) when the interval length is 800 for Huarng's distribution-based approach [6],

(v) when the interval length is 200 for Huarng's averagebased approach [6],

(vi) when the sample percentile is 0.5 for Huarng's ratiobased approach [8],

(vii) when the interval length is 800 on 4th degree model and unit number of artificial neural network hidden layers is 8 for the solution of Aladag et al. [18] method,

(viii) when the number of fuzzy sets is 15 for the solution of Cheng et al. [9] method,

(ix) when the number of fuzzy sets is 13 and the unit number of artificial neural network hidden layers is 7 for the solution of Yolcu et al. [25] method, (x) when the interval length is 400 for $Y(t)$, the number of fuzzy sets is 8 for $e(t)$, and the unit number of artificial neural network hidden layers is 6 in the fuzzy $\operatorname{ARMA}(4,3)$ model for the solution of the proposed method.

The parameters during which the best results given in Table 6 were obtained are as follows:

(i) when the number of fuzzy sets is 20 for the solution of Song and Chissom [1] method,

(ii) when the interval length is 1500 for the solution of Chen [5] method,

(iii) when the interval length on 3rd degree model is 900 for the solution of Chen [14] method,

(iv) when the interval length is 800 for Huarng's distribution-based approach [6],

(v) when the interval length is 200 for Huarng's averagebased approach [6],

(vi) when the sample percentile is 0.5 for Huarng's ratiobased approach [8],

(vii) when the interval length is 200 on 2 nd degree model and unit number of artificial neural network hidden layers is 5 for the solution of Aladag et al. [18] method,

(viii) when the number of fuzzy sets is 6 for the solution of Cheng et al. [9] method,

(ix) when the number of fuzzy sets is 7 and the unit number of artificial neural network hidden layers is 3 for the solution of Yolcu et al. [25] method,

(x) when the interval length is 300 for $Y(t)$, the number of fuzzy sets is 9 for $e(t)$, and the unit number of artificial neural network hidden layers is 4 in the fuzzy $\operatorname{ARMA}(1,2)$ model for the solution of the proposed method.

The parameters during which the best results given in Table 7 were obtained are as follows:

(i) when the number of fuzzy sets is 9 for the solution of Song and Chissom [1] method,

(ii) when the interval length is 300 for the solution of Chen [5] method,

(iii) when the interval length on 3rd degree model is 2200 for the solution of Chen [14] method,

(iv) when the interval length is 1000 for Huarng's distribution-based approach [6],

(v) when the interval length is 200 for Huarng's averagebased approach [6],

(vi) when the sample percentile is 0.5 for Huarng's ratiobased approach [8],

(vii) when the interval length is 600 on 2 nd degree model and unit number of artificial neural network hidden layers is 5 for the solution of Aladag et al. [18] method,

(viii) when the number of fuzzy sets is 9 for the solution of Cheng et al. [9] method, 
(ix) when the number of fuzzy sets is 7 and the unit number of artificial neural network hidden layers is 6 for the solution of Yolcu et al. [25] method,

(x) when the interval length is 900 for $Y(t)$, the number of fuzzy sets is 15 for $e(t)$, and the unit number of artificial neural network hidden layers is 2 in the fuzzy $\operatorname{ARMA}(2,2)$ model for the solution of the proposed method.

The parameters during which the best results given in Table 8 were obtained are as follows:

(i) when the number of fuzzy sets is 20 for the solution of Song and Chissom [1] method,

(ii) when the interval length is 900 for the solution of Chen [5] method,

(iii) when the interval length on 2nd degree model is 1400 for the solution of Chen [14] method,

(iv) when the interval length is 1000 for Huarng's distribution-based approach [6],

(v) when the interval length is 200 for Huarng's averagebased approach [6],

(vi) when the sample percentile is 0.5 for Huarng's ratiobased approach [8],

(vii) when the interval length is 1500 on 2 nd degree model and unit number of artificial neural network hidden layers is 6 for the solution of Aladag et al. [18] method,

(viii) when the number of fuzzy sets is 10 for the solution of Cheng et al. [9] method,

(ix) when the number of fuzzy sets is 7 and the unit number of artificial neural network hidden layers is 7 for the solution of Yolcu et al. [25] method,

(x) when the interval length is 900 for $Y(t)$, the number of fuzzy sets is 28 for $e(t)$, and the unit number of artificial neural network hidden layers is 10 in the fuzzy $\operatorname{ARMA}(1,1)$ model for the solution of the proposed method.

In compliance with approach in which the forecasts that have the minimum RMSE value are the best forecasts, it has been determined that the proposed method has the best forecasting performance in comparison with 9 methods solved in this paper for each of 6 applications. It can also be seen clearly that the forecasts obtained through the proposed method are very close to the test set on the graphs presented in Figures 7-11.

The values of RMSE and MAPE obtained through the proposed method for the test set have significantly lower in comparison with other methods in all applications and direction accuracy is significantly higher compared to the other methods in the literature. These results show that fuzzy $\operatorname{ARMA}(p, q)$ model considerably can increase the forecasting performance. In addition, the fact of obtaining the RMSE value as 177.24 (the lowest RMSE value obtained in other methods is 373.21) and the direction accuracy as $100 \%$ for the solution of data set 2 (Table 5) draws attention from the point of display the effect of proposed method on increasing the forecasting performance.

\section{Discussion and Conclusion}

The actual point of emphasis in this paper is the consideration that it is more realistic to use one of the AR, MA, and ARMA models in accordance with the structure of the data in the manner that it is made in linear models of the classical time series. It is a deficiency that the fuzzy time series methods in the literature mostly consist of models using only AR variables. Not using MA variables could cause the model specification error in solutions of fuzzy time series. This deficiency has been shown clearly in the applications of this study, and so it is proven that forecasting performance towards future can be significantly increased with fuzzy ARMA model compared to the fuzzy AR models. The reasoning of this is that real lifetime series are affected not only by AR variables but also by MA variables.

The effect of the structure of the model in fuzzy time series approaches within the literature has been shown with the approach of being divided to two, namely, only first and high order models. Particularly significant progresses in fuzzy AR type have been executed by increasing the forecasting performance in the stage of identification of fuzzy relations via methods such as using membership values, identifying relations through artificial neural networks, and particle swarm optimisation. However, in the applications of the proposed method, it is clearly showed that the proposed method has better performance than those of many AR methods that use the membership values or optimisation methods. For this reason, selecting both the proper model degree (first order or high order) and the proper model type (AR, MA, or ARMA) is more realistic approach in solving of real life fuzzy time series.

By means of the proposed method, it has been clearly expressed how much using a high order fuzzy ARMA model based on artificial neural networks may significantly affect the forecasting performance. Therefore, it is considered that this study will constitute basis for new fuzzy ARMA type models in future because of the fact that the proposed method is the first study of high order fuzzy ARMA time series model.

\section{Conflict of Interests}

The author declares that there is no conflict of interests regarding the publication of this paper.

\section{References}

[1] Q. Song and B. S. Chissom, "Fuzzy time series and its models," Fuzzy Sets and Systems, vol. 54, no. 3, pp. 269-277, 1993.

[2] L. A. Zadeh, "Fuzzy sets," Information and Computation, vol. 8, pp. 338-353, 1965.

[3] Q. Song and B. S. Chissom, "Forecasting enrollments with fuzzy time series-part I," Fuzzy Sets and Systems, vol. 54, no. 1, pp. 19, 1993.

[4] Q. Song and B. S. Chissom, "Forecasting enrollments with fuzzy time series-part II," Fuzzy Sets and Systems, vol. 62, no. 1, pp. $1-8,1994$.

[5] S.-M. Chen, "Forecasting enrollments based on fuzzy time series," Fuzzy Sets and Systems, vol. 81, no. 3, pp. 311-319, 1996. 
[6] K. Huarng, "Effective lengths of intervals to improve forecasting in fuzzy time series," Fuzzy Sets and Systems, vol. 123, no. 3, pp. 387-394, 2001.

[7] K. Huarng and T. H.-K. Yu, "The application of neural networks to forecast fuzzy time series," Physica A, vol. 363, no. 2, pp. 481491, 2006

[8] K. Huarng and T. H. K. Yu, "Ratio-based lengths of intervals to improve fuzzy time series forecasting," IEEE Transactions on Systems, Man, and Cybernetics, Part B: Cybernetics, vol. 36, no. 2, pp. 328-340, 2006.

[9] C.-H. Cheng, G.-W. Cheng, and J.-W. Wang, "Multi-attribute fuzzy time series method based on fuzzy clustering," Expert Systems with Applications, vol. 34, no. 2, pp. 1235-1242, 2008.

[10] U. Yolcu, E. Egrioglu, V. R. Uslu, M. A. Basaran, and C. H. Aladag, "A new approach for determining the length of intervals for fuzzy time series," Applied Soft Computing, vol. 9, no. 2, pp. 647-651, 2009.

[11] T. H.-K. Yu and K.-H. Huarng, "A bivariate fuzzy time series model to forecast the TAIEX," Expert Systems with Applications, vol. 34, no. 4, pp. 2945-2952, 2008.

[12] E. Egrioglu, C. H. Aladag, U. Yolcu, V. R. Uslu, and N. A. Erilli, "Fuzzy time series forecasting method based on GustafsonKessel fuzzy clustering," Expert Systems with Applications, vol. 38, no. 8, pp. 10355-10357, 2011.

[13] H. J. Sadaei and M. H. Lee, "Multilayer stock forecasting model using fuzzy time series," The Scientific World Journal, vol. 2014, Article ID 610594, 10 pages, 2014.

[14] S.-M. Chen, "Forecasting enrollments based on high-order fuzzy time series," Cybernetics and Systems, vol. 33, no. 1, pp. 116, 2002.

[15] S.-M. Chen and N.-Y. Chung, "Forecasting enrollments using high-order fuzzy time series and genetic algorithms," International Journal of Intelligent Systems, vol. 21, no. 5, pp. 485-501, 2006.

[16] T. A. Jilani and S. M. A. Burney, "M-factor high order fuzzy time series forecasting for road accident data," Advances in Soft Computing, vol. 41, pp. 246-254, 2007.

[17] L.-W. Lee, L.-H. Wang, and S.-M. Chen, "Temperature prediction and TAIFEX forecasting based on high-order fuzzy logical relationships and genetic simulated annealing techniques," Expert Systems with Applications, vol. 34, no. 1, pp. 328-336, 2008.

[18] C. H. Aladag, M. A. Basaran, E. Egrioglu, U. Yolcu, and V. R. Uslu, "Forecasting in high order fuzzy times series by using neural networks to define fuzzy relations," Expert Systems with Applications, vol. 36, no. 3, pp. 4228-4231, 2009.

[19] E. Egrioglu, C. H. Aladag, U. Yolcu, V. R. Uslu, and M. A. Basaran, "A new approach based on artificial neural networks for high order multivariate fuzzy time series," Expert Systems with Applications, vol. 36, no. 7, pp. 10589-10594, 2009.

[20] E. Egrioglu, C. H. Aladag, U. Yolcu, V. R. Uslu, and M. A. Basaran, "Finding an optimal interval length in high order fuzzy time series," Expert Systems with Applications, vol. 37, no. 7, pp. 5052-5055, 2010.

[21] H. J. Sadaei, R. Enayatifar, A. H. Abdullah, and A. Gani, "Shortterm load forecasting using a hybrid model with a refined exponentially weighted fuzzy time series and an improved harmony search," International Journal of Electrical Power and Energy Systems, vol. 62, pp. 118-129, 2014.

[22] P.-T. Chang, "Fuzzy seasonality forecasting," Fuzzy Sets and Systems, vol. 90, no. 1, pp. 1-10, 1997.
[23] Q. Song, "Seasonal forecasting in fuzzy time series," Fuzzy Sets and Systems, vol. 107, no. 2, pp. 235-236, 1999.

[24] E. Egrioglu, C. H. Aladag, U. Yolcu, M. A. Basaran, and V. R. Uslu, "A new hybrid approach based on SARIMA and partial high order bivariate fuzzy time series forecasting model," Expert Systems with Applications, vol. 36, no. 4, pp. 7424-7434, 2009.

[25] U. Yolcu, C. H. Aladag, E. Egrioglu, and V. R. Uslu, “Time-series forecasting with a novel fuzzy time-series approach: an example for Istanbul stock market," Journal of Statistical Computation and Simulation, vol. 83, no. 4, pp. 599-612, 2013.

[26] E. Egrioglu, V. R. Uslu, U. Yolcu, M. A. Basaran, and C. H. Aladag, "A new approach based on artificial neural networks for high order bivariate fuzzy time series," in Applications of Soft Computing, J. Mehnen, M. Köppen, A. Saad, and A. Tiwari, Eds., vol. 58 of Advances in Intelligent and Soft Computing, pp. 265273, Springer, Berlin, Germany, 2009.

[27] V. R. Uslu, C. H. Aladag, U. Yolcu, and E. Egrioğlu, "A new hybrid approach for forecasting a seasonal fuzzy time series," in International Symposium Computing Science and Engineering Proceeding Book, pp. 1152-1158, 2010.

[28] F. Alpaslan, O. Cagcag, C. H. Aladag, U. Yolcu, and E. Egrioglu, "A novel seasonal fuzzy time series method," Hacettepe Journal of Mathematics and Statistics, vol. 41, no. 3, pp. 375-385, 2012.

[29] E. Egrioglu, U. Yolcu, C. H. Aladag, and C. Kocak, "An ARMA type fuzzy time series forecasting method based on particle swarm optimization," Mathematical Problems in Engineering, vol. 2013, Article ID 935815, 12 pages, 2013.

[30] C. Kocak, "First-order ARMA type fuzzy time series method based on fuzzy logic relation tables," Mathematical Problems in Engineering, vol. 2013, Article ID 769125, 12 pages, 2013.

[31] E. Oztemel, Artificial Neural Networks, Papatya Publications, İstanbul, Turkey, 2006.

[32] J. M. Zurada, Introduction of Artificial Neural Systems, West Publishing, New York, NY, USA, 1992.

[33] K. Levenberg, "A method for the solution of certain nonlinear problems in least squares," The Quarterly of Applied Mathematics, vol. 2, pp. 164-168, 1944.

[34] Ö. Kişi, "Multi-layer perceptrons with Levenberg-Marquardt training algorithm for suspended sediment concentration prediction and estimation," Hydrological Sciences Journal, vol. 49, no. 6, pp. 1025-1040, 2004. 


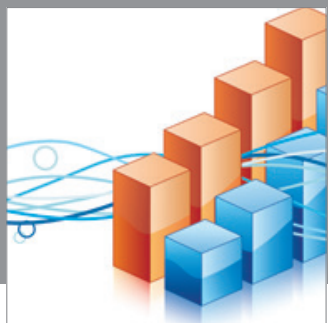

Advances in

Operations Research

mansans

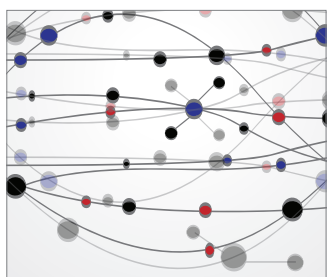

The Scientific World Journal
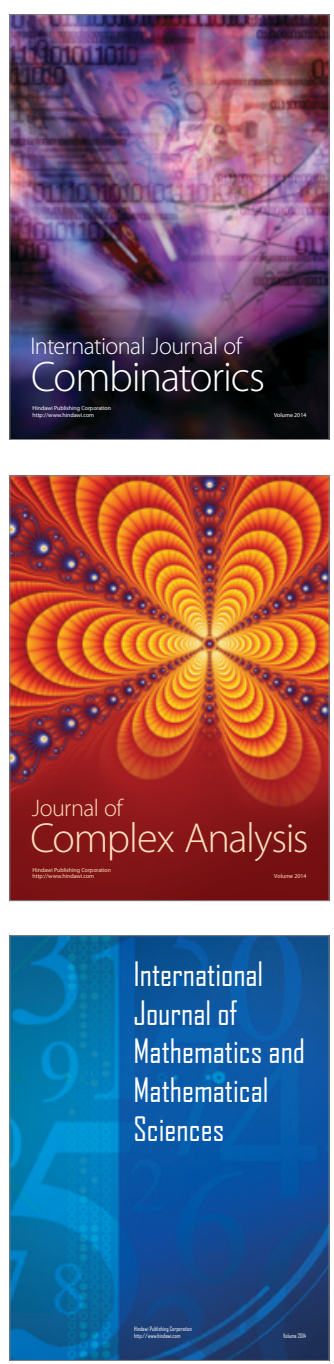
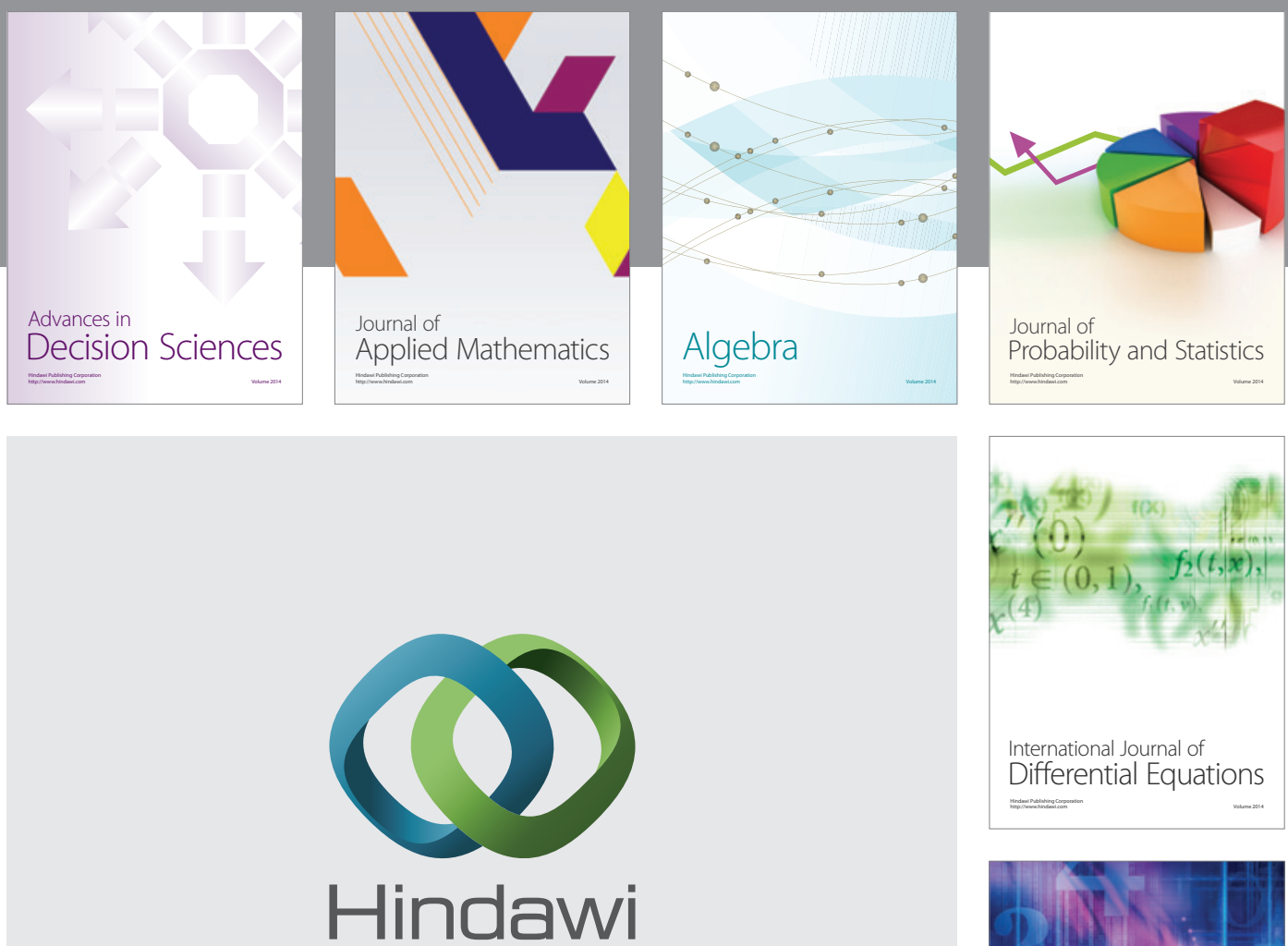

Submit your manuscripts at http://www.hindawi.com
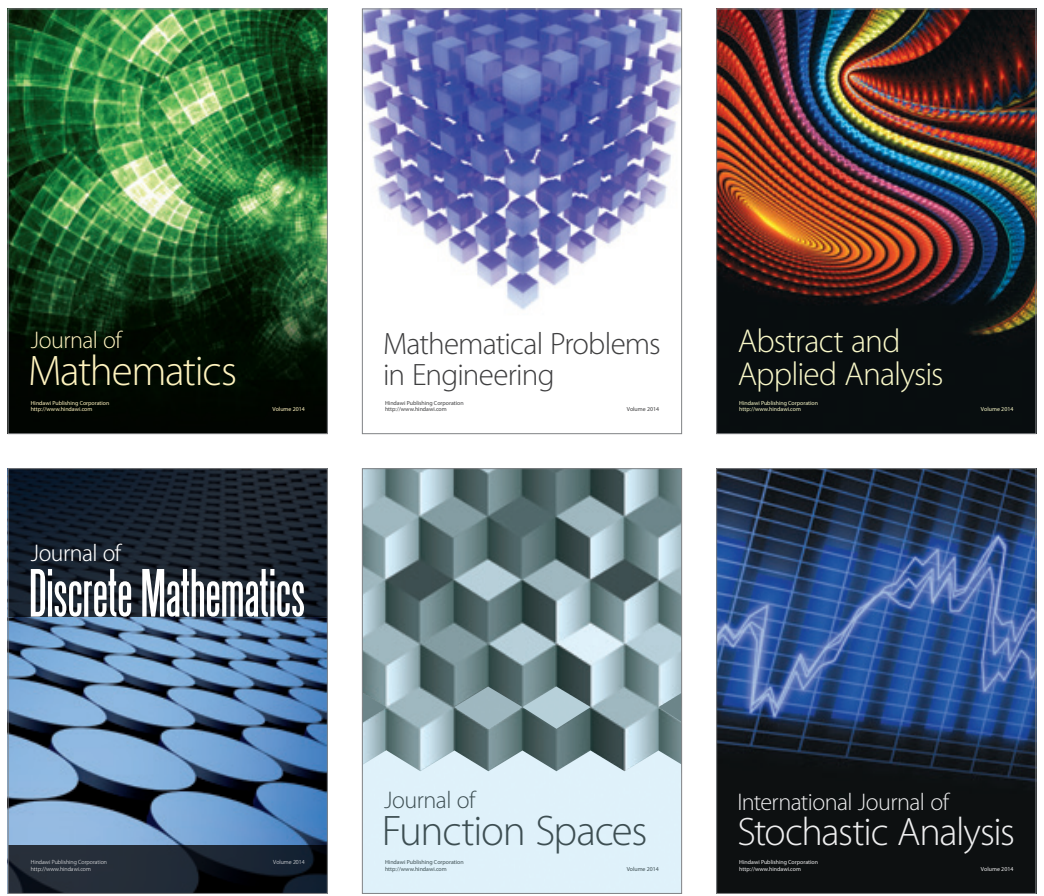

Journal of

Function Spaces

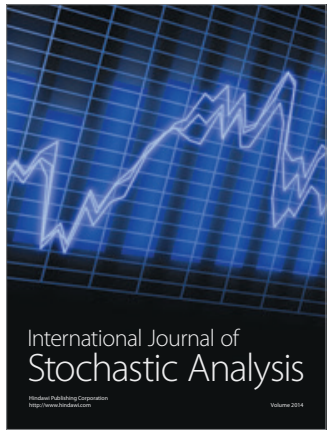

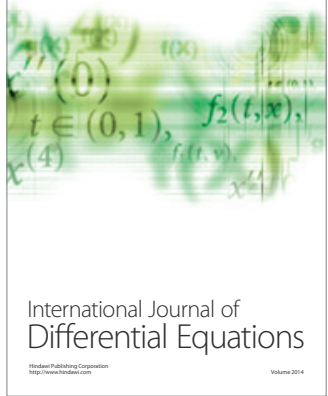
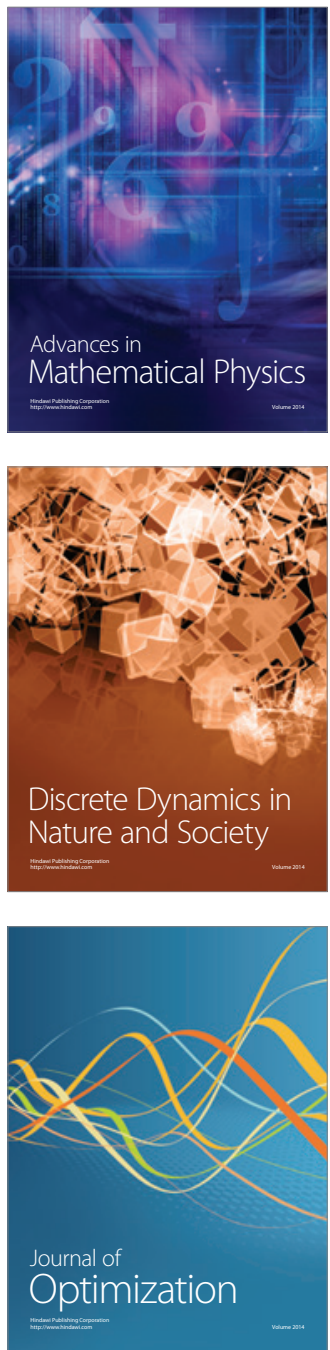